\title{
Cicer echinospermum P.H. Davis genotiplerinde nohut yaprak galeri sineğine [Liriomyza cicerina Rond. (Diptera: Agromyzidae)] dayanıklılığın değerlendirilmesi
}

\author{
Assessment of leaf miner [Liriomyza cicerina Rond. (Diptera: Agromyzidae)] \\ resistance in Cicer echinospermum P.H. Davis genotypes
}

\author{
Hatice SARI $^{1}$, Duygu SARI ${ }^{1}$, Alper ADAK ${ }^{1}$, Hüseyin ÇANCI ${ }^{1}$, Cengiz İKTEN ${ }^{2}$, Fedai ERLER ${ }^{2}$, Tolga \\ YILDIRIM $^{3}$, Cengiz TOKER ${ }^{1}$, Abdullah KAHRAMAN ${ }^{4}$
}

${ }^{1}$ Akdeniz Üniversitesi, Ziraat Fakültesi, Tarla Bitkileri Bölümü, Antalya, Türkiye

${ }^{2}$ Akdeniz Üniversitesi, Ziraat Fakültesi, Bitki Koruma Bölümü, Antalya, Türkiye

${ }^{3}$ Akdeniz Üniversitesi, Fen Fakültesi, Biyoloji Bölümü, Antalya, Türkiye

${ }^{4}$ Harran Üniversitesi, Ziraat Fakültesi, Tarla Bitkileri Bölümü, Şanlıurfa, Türkiye

Sorumlu yazar (Corresponding author): A. Kahraman, e-posta (e-mail): kahraman@ harran.edu.tr

\section{MAKALE BİLGISİ}

Alınış tarihi 06 Ekim 2017

Düzeltilme tarihi 21 Kasim 2017

Kabul tarihi 23 Kasim 2017

\section{Anahtar Kelimeler:}

Nohut

Cicer echinospermum

Yaprak galeri sineği

Liriomyza cicerina

\begin{abstract}
öz
Nohut yaprak galeri sineği [Liriomyza cicerina Rond. (Diptera: Agromyzidae)] dikkate değer verim kayıplarına yol açtığı için Türkiye'deki en önemli ve yaygın nohut (Cicer arietinum $\mathrm{L}$ ) zararlılardan biridir. Nohut yaprak galeri sineği zararının üstesinden gelmek için en pratik, çevreci ve ekonomik çözümlerden biri dayanıklı çeşitlerin kullanılmasıdır. Bu çalışma tarımı yapilan nohut ile melezlenebilen Cicer echinospermum P.H. Davis genotiplerinin nohut yaprak galeri sineğine dayanıklılık için değerlendirilmesini amaçlamıştır. C. echinospermum türüne ait 22 genotip ve nohut yaprak galeri sineğine duyarlı tarımı yapılan bir genotip tarla koșullarında bir 1-9 görsel ölçek kullanılarak değerlendirilmiștir. Hassas genotip (CA 2969) her 10 sırada tekrarlanmıştır. Genotipler 1-9 görsel ölçeği üzerinden hassas genotip 8 ölçek değeri aldıktan sonra değerlendirilmiștir. C. echinospermum genotiplerinin büyük çoğunluğu dayanıklı olarak bulunmuştur. Bu dayanıklılık kaynakları C. echinospermum tarımı yapılan nohut ile melezlenebildiği için ıslah programlarında kullanılabilecektir.
\end{abstract}

\section{ARTICLE INFO}

Received 06 October 2017

Received in revised form 21 November 2017

Accepted 23 November 2017

\section{Keywords:}

Chickpea

Cicer echinospermum

Leaf miner

Liriomyza cicerina

\begin{abstract}
The chickpea leaf miner [Liriomyza cicerina Rond. (Diptera: Agromyzidae)] is one of the most important and common insect pests of chickpea (Cicer arietinum L) since it causes substantial yield losses in Turkey. The most practical, environmental and economical solution to overcome chickpea leaf miner damage is the utilization of resistant cultivars. The present study aimed to evaluate Cicer echinospermum P.H. Davis genotypes which can be hybridized with cultivated chickpea for resistance to chickpea leaf miner. A total of 22 genotypes of $C$. echinospermum and a genotype of the cultivated chickpea, sensitive to chickpea leaf miner, were evaluated using a visual 1-9 scale under field conditions. A sensitive chickpea (CA 2969) was repeated in every ten rows. Genotypes were evaluated after the sensitive genotype had a rating of 8 on 1-9 scale. Most of the genotypes of $C$. echinospermum were found to be resistant. These resistant resources will be used in breeding programs since $C$. echinospermum is cross-compatible with the cultivated chickpea.
\end{abstract}

\section{Giriş}

Tarımı yapılan nohut (Cicer arietinum L.) 2014 yılı verilerine göre dünyada ekiliş alanları bakımından serin iklim baklagiller arasında ilk sirada yer almaktadır. Nohut dünyada yaklaşık 13.5 milyon hektar alanda yetiştirilmekte ve hektara $968 \mathrm{~kg}$ verim alınmaktadır (FAOSTAT 2017). Türkiye'de nohut ekim alanı 359304 ha, üretimi 460000 ton ve verim yaklaşık hektara 1280 kg'dır (TUIK 2017). Tarımı yapılan nohudun hektara $4000 \mathrm{~kg}$ (Singh 1990) üstünde verim potansiyeli olmasına rağmen, alınabilen gerçek verim bu oranın çok altındadır. Bu verim kaybının canlı ve cansız stres faktörlerinin bileşiminden kaynaklandığı düşünülmektedir (Canci ve Toker 2009). Akdeniz Havzası'nda en fazla ürün kaybına neden olan 
canlı stres faktörlerinden biri nohut yaprak galeri sineği [Liriomyza cicerina Rond. (Diptera: Agromyzidae] olarak bildirilmiştir (Giray 1970; Reed ve ark. 1987; Singh ve Weigand 1994; Cikman ve ark. 2006; Cikman ve Civelek 2006; El-Bouhssini ve ark. 2008; Toker ve ark. 2010; Toker ve ark. 2012). Nohut yaprak galeri sineği baklagiller (Leguminosae/Fabaceae) familyasından olan kültür bitkilerinden beslenmekle birlikte öncelikli konukçusu tarımı yapılan nohuttur (Civelek ve ark. 2008).

Yaprak galeri sineğinin dişisi konukçu bitkinin yaprak ve yaprakçıklarını ovipozitörleri ile delerek yaklaşı altı adet yumurta bırakır. Dört günlük süreçten sonra larvalar parankima dokusu boyunca tüneller açar ve biraktıkları salgı nedeniyle yaprakçıklar üzerinde beyaz noktacıklar oluşturmaktadır. Yoğun bulaşmalarda larvaların yaptığı zarar, bitkinin fotosentez alanının azalmasına, yaprakçıkların düşmesine, bitkinin zayıflamasına ve sonuçta verimde önemli kayıplara neden olmaktadır. Nohutta yaprak galeri sineğine bağlı zararın \% 40 kadar verim kaybına neden olduğu bildirilmektedir (Reed ve ark. 1987; Kaplan 2008). Nohut yaprak galeri sineği kimyasal mücadele, kültürel uygulamalar, biyolojik mücadele ve konukçu bitki dayanıklılığ1 ile kontrol altına alınabilmektedir (Reed ve ark. 1987). Mücadele için kullanılan kimyasallar insan ve çevre sağlığı üzerinde risk taşıyabilmektedir. Ayrıca nohut marjinal alanlarda tarımı yapıldığından kimyasal kullanımı ve biyolojik mücadele birim maliyeti artırması nedeniyle ekonomik olmamaktadır. Yaprak galeri sineğinin kontrolü için en uygun uygulamanın konukçu bitki dayanıklılı̆̆ı ve kültürel uygulamalar olduğu bildirilmektedir (Weigand 1990; Singh ve Weigand 2006).

Tarımı yapılan nohutta dayanıklılık kaynaklarının sınırlı ve yetersiz olmas1, tek y1llık nohut türlerinin yaprak galeri sineğine dayanıklılık bakımından gözlemlenmesini zorunlu hale getirmiştir. Singh ve Weigand (1994), farklı türlerden 200 Cicer genotipinin yaprak galeri sineğine dayanıklılık bakımından gözlemlemiş ve $C$. cuneatum Hochst. ex Rich., C. judaicum Boiss., C. pinnatifidum Jaub. \& Spach. ve C. reticulatum Ladiz. türlerinde dayanıklılık kaynakları belirlemiştir. Robertson ve ark. (1995) C. bijugum K.H. Rech., C. echinospermum P.H.
Davis, C. pinnatifidum, C. judaicum, C. chorassanicum (Bge) M. Pop. ve $C$. reticulatum türlerinin bazı genotiplerinde yaprak galeri sineğine dayanıklılık kaynakları olduğunu bildirmiş̧tir. Bulunan dayanıklılık kaynaklarından sadece C. echinospermum ve $C$. reticulatum tarımı yapılan nohut ile melezlenebilmektedir (Ladizinsky ve Adler 1976; Koseoglu ve ark. 2017; Adak ve ark. 2017). Dünyada ulusal ve uluslararası gen bankalarında $C$. echinospermum türünün 10 genotipi bulunmaktadır. Son zamanlarda yapılan bir toplama çalışması ile bu sayı 272 genotipe kadar artırılmıştır (Toker ve ark. 2014; Talip ve ark. 2018). Yeni toplanan materyallerin yaprak galeri sineğine dayanıklılık durumları henüz belirlenmemiştir. Bu çalışmada, C.echinospermum genotiplerinde yaprak galeri sineğine dayanıklı genotiplerin belirlenmesi amaçlanmıştır.

\section{Materyal ve Yöntem}

\subsection{Materyal}

Çalışmada 22 C. echinospermum ve bir hassas kontrol (CA 2969) olmak üzere toplam 23 genotip değerlendirilmiştir (Çizelge 1). Hassas genotip her 10 sırada bir tekrarlı ekilerek 19 görsel ölçek ile değerlendirilmiştir. Genotipler, 2016 ve 2017 yıllarında yaprak galeri sineğine dayanıklılık için incelenmiştir. Genotipler her iki yıl Şubat ayında Akdeniz Üniversitesi, Antalya, araştırma deneme alanlarında $5 \mathrm{~cm}$ derinliğinde ekilmiştir. Deneme tesadüf blokları deneme desenlerine göre üç tekrarlamalı olarak yürütülmüştür. Sıra arası $45 \mathrm{~cm}$, sıra üzeri $10 \mathrm{~cm}$ mesafe olacak şekilde 2m' lik sıralara ekim yapılmıştır.

\subsection{Yaprak galeri sineğine karşı dayanıklılık taraması}

Bitkiler tarla şartlarında doğal epidemi altında incelenmiştir. Dayanıklılık taraması fide dönemi, çiçeklenme dönemi ve $\% 50$ bakla bağlama döneminde tekrarlanarak her genotip için en yüksek değer kaydedilmiştir. Çalışmada yaprak galeri sineğine dayanıklılık gözlemi Singh ve Weigand (1994) tarafından bildirilen 1-9 görsel ölçeğinde (Çizelge 2) bazı düzenlemeler yapılarak kullanılmıştır. Çizelge 2'ye göre 1-4 arası dayanıklı, 5 toleransl1, 6-9 arası ise hassas olarak değerlendirilmiştir.

Çizelge 1. Cicer echinospermum genotipleri ve toplama yerleri.

Table 1. Genotypes of Cicer echinospermum and collection sites.

\begin{tabular}{|c|c|c|c|c|c|c|}
\hline No & Genotip & Hat No & Şehir & Enlem & Boylam & Rakım (m) \\
\hline 1 & TR 82945 & $163 a$ & Şanlıurfa & 37.780171 & 39.172984 & 738.9 \\
\hline 2 & TR 82945 & $163 b$ & Şanlıurfa & 37.780171 & 39.172984 & 738.9 \\
\hline 3 & TR 82945 & $163 c$ & Şanlıurfa & 37.780171 & 39.172984 & 738.9 \\
\hline 4 & TR 82951 & $170 \mathrm{c}$ & Şanlıurfa & 37.779714 & 39.171856 & 737.5 \\
\hline 5 & TR 82954 & $175 a$ & Şanlıurfa & 37.779745 & 39.171788 & 737.8 \\
\hline 6 & TR 82954 & $175 b$ & Şanlıurfa & 37.779745 & 39.171788 & 737.8 \\
\hline 7 & TR 82954 & $175 c$ & Şanlıurfa & 37.779745 & 39.171788 & 737.8 \\
\hline 8 & TR 82956 & $177 \mathrm{c}$ & Şanlıurfa & 37.779771 & 39.171770 & 738.9 \\
\hline 9 & TR 82958 & $195 a$ & Diyarbakır & 38.011241 & 39.374761 & 841.6 \\
\hline 10 & TR 82958 & $195 b$ & Diyarbakır & 38.011241 & 39.374761 & 841.6 \\
\hline 11 & TR 82958 & $195 c$ & Diyarbakır & 38.011241 & 39.374761 & 841.6 \\
\hline 12 & TR 82981 & 320 & Şanlıurfa & 37.474158 & 39.561448 & 856.6 \\
\hline 13 & TR 82983 & $323 a$ & Şanlıurfa & 37.473346 & 39.563619 & 861.3 \\
\hline 14 & TR 82983 & $323 b$ & Şanlıurfa & 37.473346 & 39.563619 & 861.3 \\
\hline 15 & TR 82983 & $323 c$ & Şanlıurfa & 37.473346 & 39.563619 & 861.3 \\
\hline 16 & TR 83132 & 408 & Şanlıurfa & 37.821734 & 39.641475 & 1124.3 \\
\hline 17 & TR 83133 & 409 & Şanlıurfa & 37.821720 & 39.641489 & 1123.5 \\
\hline 18 & TR 83135 & 412 & Şanlıurfa & 37.821118 & 39.641649 & 1125.8 \\
\hline 19 & TR 85634 & $438 b$ & Şanlıurfa & 37.372919 & 39.764105 & 771.0 \\
\hline 20 & TR 85641 & 446 & Şanlıurfa & 37.372919 & 39.764105 & 771.0 \\
\hline 21 & TR 85642 & 448 & Şanlıurfa & 37.372919 & 39.764105 & 771.0 \\
\hline 22 & TR 85648 & 454 & Şanlıurfa & 37.372919 & 39.764105 & 771.0 \\
\hline
\end{tabular}


Çizelge 2. Nohut yaprak galeri sineğine dayanıklılık için görsel 1-9 ölçeği.

Table 2. A 1-9 visual scale for resistance to chickpea leaf miner.

\begin{tabular}{cll}
\hline Ölçek & Dayanıklılık & Genotiplerin görünümü \\
\hline 1 & Tam dayanıklı & Hiç bir zarar belirtisi yok \\
2 & Çok dayanıklı & Çok dikkatli bakıldı̆̆ında birkaç yaprakçıkta zarar \\
3 & Dayanıklı & Yaprakçıkların \% 20’ sinden az zarar var, yaprak dökülmesi yok \\
4 & Orta derecede dayanıklı & Yaprakçıkların \% 21-30 arasında zarar var, yaprak dökülmesi yok \\
5 & Toleranslı & Yaprakçıkların \% 31-40 arasında zarar var, bitkilerin yarısından daha azında dökülme var \\
6 & Orta derecede toleranslı & Yaprakçıkların \% 41-50 arasında zarar var, bitkilerin alt yapraklarında \% 10’a kadar dökülme var \\
7 & Hassas & Yaprakçıkların \% 51-70 arasında zarar var, yapraklarda \% 10-20 arası dökülme var \\
8 & Yüksek oranda hassas & Yaprakçıkların \% 70-90 arasında zarar var, yapraklarda \% 21-30 arası dökülme var \\
9 & Tam hassas & Yaprakçıkların neredeyse hepsinde (\% 90) zarar var ve yaprakların \% 31 ‘den fazlasında dökülme var \\
\hline
\end{tabular}

\subsection{Istatistiki analizler}

Nohut yaprak galeri sineğine dayanıklılık verileri yüzdeye çevrilmiş ve SPSS 22 programı kullanılarak varyans analizine tabi tutulmuştur.

\section{Bulgular}

Genotipler arasında istatistiki olarak önemli $(\mathrm{P} \leq 0.01)$ fark olduğu belirlenirken, genotip $\times$ y1l interaksiyonunun önemli olmadığı belirlenmiştir. $\mathrm{Bu}$ nedenle yıllar birleşik verilmiştir. Çalışmada değerlendirilen 22 C. echinospermum genotipin (163a, 163b, 163c,170c, 175a, 175b, 175c, 177c, 195a, 195b, 195c, 320, 323a, 323b, 323c, 408, 409, 412, 438b, 446, 448 ve 454) 2 ile 5 arasında görsel ölçek değeri aldığı belirlenmiştir. Yaprak galeri sineğine dayanıklılık bakımından genotiplerin yaklaşık \% 65'inin dayanıklı, \% 35'inin ise toleranslı olduğu belirlenmiştir (Şekil 1). Genotiplerden bir tanesi (446) 2 değeri ile yüksek oranda dayanıklı, beş tanesi ise dayanıklı (3 görsel ölçek değeri alanlar) bulunmuştur. Sekiz genotipin orta derecede dayanıklı (4 görsel ölçek değeri alanlar) olduğu gözlemlenirken, hassas kontrol CA 2969 nohut genotipinin ise yüksek oranda hassas (8 görsel ölçek değeri) olduğu belirlenmiştir (Şekil 2).

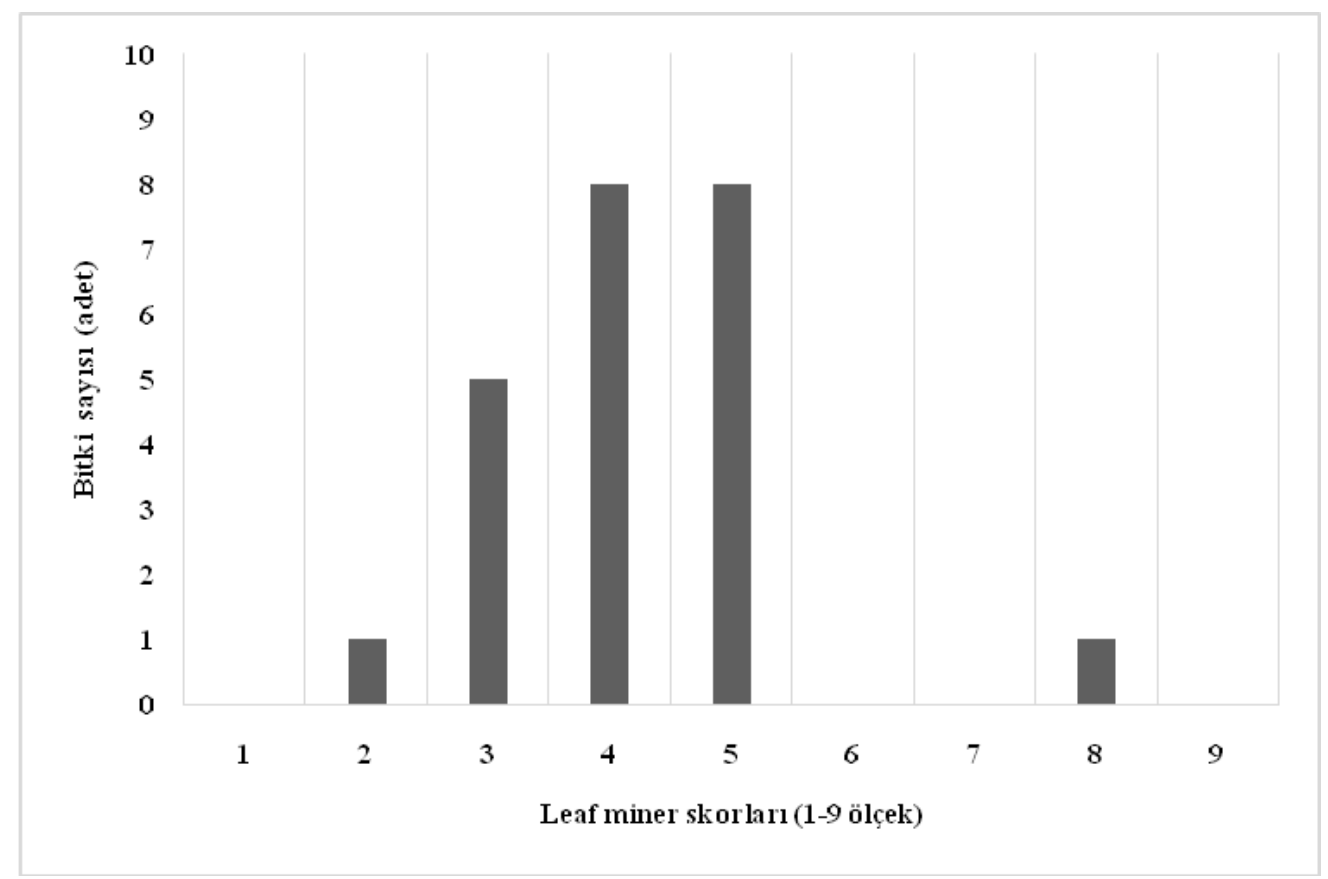

Şekil 1. 1-9 görsel ölçek üzerinden nohut yaprak galeri sineğine dayanıklı genotiplerin dağılımı.

Figure 1. Distribution of genotypes for resistance to leaf miner on 1-9 visual scale. 


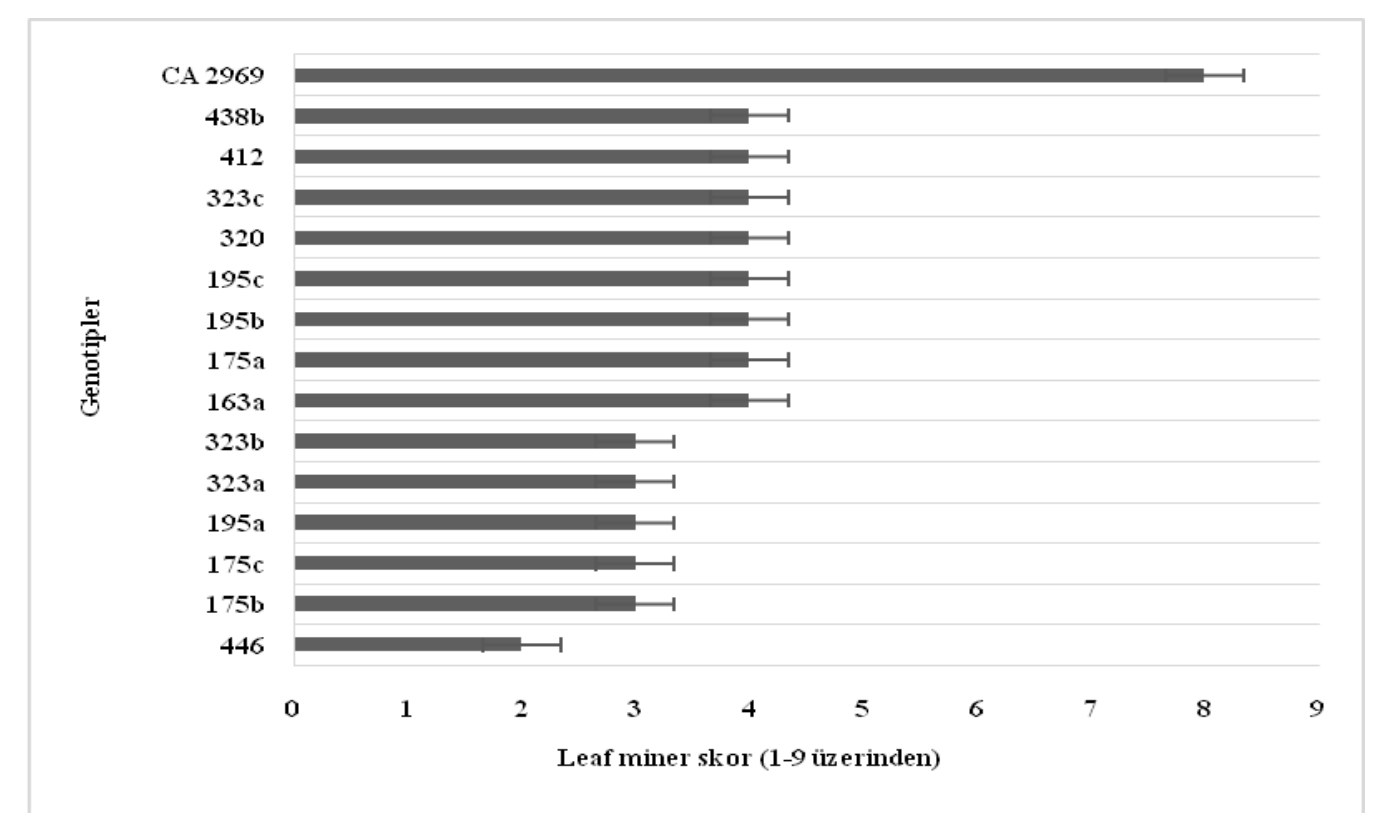

Şekil 2. Cicer echinospermum genotipleri ve duyarlı kontrolde nohut yaprak galeri sineğine dayanıklılık (Barlar ortalama \pm standart hatalardır). Figure 2. Resistance to chickpea leaf miner in genotypes of Cicer echinospermum and sensitive check (Bars indicate mean \pm standard errors).

\section{Tartışma ve Sonuç}

Nohut yaprak galeri sineğine karşı dayanıklılık ile ilgili verilerin, 1-9 görsel ölçeğine göre 2 ila 5 arasında değiştiği belirlenmiş̧ir (Şekil 1). Araştırma sonuçlarına göre en dayanıklı kaynak 2 skoru ile 446 C. echinospermum genotipi olmuştur. Buna ilaveten 175a, 175b, 195a, 323a ve 323b genotipleri 3 görsel ölçek değeri alarak yaprak galeri sineğine karşı dayanıklı oldukları belirlenmiştir (Şekil 2).

Reed ve ark. (1987), çalışmalarında 9500 adet nohut genotipinden 21 tanesini yaprak galeri sineğine karşı orta derecede dayanıklı bulduklarını bildirmişlerdir. Singh ve Weigand (1994), nohut türlerinde yaprak galeri sineğine karş1 dayanıklılık belirleme çalışmalarında beş adet C. echinospermum türünde tarama yapmışlardır. Araştırma sonuçlarına göre $C$. echinospermum genotiplerinde bir dayanıklılık kaynağı bulduklarını bildirmektedirler. $\mathrm{Bu}$ çalışmada ise C. echinospermum türüne ait 22 adet genotipten 14'ü dayanıklı (2 ile 4 arasında görsel ölçek değeri alarak) bulunmuştur.

Singh ve Weigand (2006), üç nohut 1slah hattını (ILC 3800, ILC 5901 ve ILC 7738) yaprak galeri sineğine dayanıklı olarak kayıt altına almışlardır. Buna ilaveten Toker ve ark. (2010) aynı ıslah hatlarının dayanıklılık kaynağı olduklarını doğrulamışlardır. Robertson ve ark. (1995), bu çalışmanın sonuçlarını doğrular nitelikte farklı nohut türlerinde (C. bijugum K.H. Rech., C. echinospermum P.H. Davis, C. pinnatifidum Jaub. ve Spach., $C$. judaicum Boiss., $C$. chorassanicum (Bge) M. Pop. ve $C$. reticulatum Ladiz.) yaprak galeri sineğine karş1 dayanıklılık kaynakları bulduklarını bildirmişlerdir. Talip ve ark. (2017) C. reticulatum ve C. echinospermum türlerinde canlı ve cansız streslere dayanıklılık kaynaklarını vermiștir. Nohut yaprak galeri sineğine dayanıklı kaynakların yeterli olmayışı, özellikle tarımı yapılan nohut ile melezlenebilir (Kazan ve ark. 1993; Singh ve Ocampo 1997; Singh ve ark. 2015; Kahraman ve ark. 2017) olan C.echinospermum yabani türünden gelecek olan dayanıklı melez hatlara ihtiyaç duyulmasına neden olmaktadır.
Sonuç olarak, C.echinospermum genotipinde bulunan dayanıklılık kaynaklarının, C.echinospermum türünün tarımı yapılan nohut ile başarılı bir şekilde melezlenebildiğinden dolayı nohut yaprak galeri sineğine dayanıklı çeşit geliştirme çalışmalarında kullanılabileceği kanısına varılmıştır.

\section{Kaynaklar}

Adak A, Sari D, Sari H, Toker C (2017) Gene effects of Cicer reticulatum Ladiz. on qualitative and quantative traits in the cultivated chickpea. Plant Breeding DOI: 10.1111/pbr.12547.

Canci H, Toker C (2009) Evaluation of annual wild Cicer species for drought and heat resistance under field conditions. Genetic Resources and Crop Evolution 56: 1-6.

Cikman E, Beyarslan A, Civelek HS (2006) Parasitoids of leaf miners (Diptera: Agromyzidae) from Southeast Turkey with 3 new records. Turkish Journal of Zoology 30: 167-173.

Cikman E, Civelek HS (2006) Population densities of Liriomyza cicerina (Rondani, 1875) (Diptera: Agromyzidae) on Cicer arietinum L. (Leguminosae: Papilionoidea) in different irrigated conditions. Turkish Journal of Entomology 30: 3-10.

Civelek HS, Dursun O, Eskin A, Taç G (2008) Türkiye Agromyzidae (Diptera) faunası üzerinde bir inceleme ve tür listesi. Anadolu Üniversitesi Bilim ve Teknoloji Dergisi 9: 1-16.

El-Bouhssini M, Mardini K, Malhotra RS, Joubi A, Kagka N (2008) Effects of planting date, varieties and insecticides on chickpea leaf miner (Liriomyza cicerina R.) infestation and the parasitoid Opius monilicornis F. Crop Protection 27: 915-919.

FAOSTAT (2017) İstatistiksel veri tabanı. http://www.fao.org/. Erişim Ağustos 2017.

Giray H (1970) Liriomyza cicerina Rond. (Diptera: Agromyzidae)'nin morfolojik karakterleri, kısa biyolojisi ve zarar şekli üzerinde araştırmalar. Ege Üniversitesi Ziraat Fakültesi Ofset Atölyesi, Bornova, İzmir, s. 34.

Kahraman A, Pandey A, Khan MK, Lindsay D, Moenga S, Vance L, Bergmann E, Carrasquilla-Garcia N, Shin M-G, Chang PL, von Wettberg EJB, Tar'an B, Cook DR, Penmetsa RV (2017) Distinct subgroups of Cicer echinospermum are associated with hybrid 
sterility and hybrid breakdown in interspecific crosses with cultivated chickpea. Crop Science 57: 3101-3111.

Kaplan M (2008) Azadirachtin ve cyromazine preparatlarının nohutta zararlı olan Liriomyza cicerina (Rondani) (Diptera: Agromyzidae) larvalarına etkisinin araştırılması. Yüksek Lisans Tezi, Harran Üniversitesi Fen Bilimleri Enstitüsü, Şanlıurfa.

Kazan K, Muehlbauer FJ, Weeden NW, Ladizinsky G (1993) Inheritance and linkage relationships of morphological and isozyme loci in chickpea (Cicer arietinum L). Theor Appl Genet 86: 417-426.

Koseoglu K, Adak A, Sari D, Sari H, Ceylan FO, Toker C (2017) Transgressive segregations for yield criteria in reciprocal interspecific crosses between Cicer arietinum L. and C. reticulatum Ladiz. Euphytica 213: 116.

Ladizinsky G, Adler A (1976) The origin of chickpea Cicer arietinum L. Euphytica 25: 211-217.

Reed W, Cardona C, Sithanantham S, Lateef SS (1987) Chickpea insect pest and their control. In: Saxena MC, Singh KB (Eds), The Chickpea. CAB International, Wallingford, Oxon, UK, pp. 283-318.

Robertson LD, Singh KB, Ocampo B (1995) A catalog of annual wild Cicer species. International Center for Agricultural Research in the Dry Areas (ICARDA), P.O. Box 5466, Aleppo, Syria, pp. 171.

Singh KB (1990) Prospects of developing new genetic material and breeding methodologies for chickpea improvement. In: Saxena MC, Cubero JI, Wery J, (Eds), Present Status and Future Prospects of Chickpea Crop Production and Improvement in the Mediterranean Countries. Options Mediterraneennes-Serie-Seminaries-no 9-CIHEAM, Paris, pp. 43-50.

Singh, KB, Weigand S (1994) Identification of resistant sources in Cicer species to Liriomyza cicerina. Genetic Resources and Crop Evolution 41: 75-79.

Singh KB, Ocampo B (1997) Exploitation of wild Cicer species for yield improvement in chickpea. Theor. Appl. Genet 95: 418-423.
Singh KB, Weigand S (2006) Registration of three leaf miner-resistant chickpea germplasm lines: ILC 3800, ILC 5901, and ILC 7738. Crop Science 36: 472-472.

Singh M, Kumar K, Bisht IS, Dutta M, Rana MK, Rana JC, Bansal CK, Sarker A (2015) Exploitation of wild annual Cicer species for widening the gene pool of chickpea cultivars. Plant Breed 134: 186-192.

Talip M, Adak A, Kahraman A, Berger J, Sari D, Sari H, Penmetsa RV, von Wettberg EJ, Cook DR, Toker C (2018) Agro-Morphological traits of Cicer reticulatum Ladizinsky in comparison to $C$. echinospermum P.H. Davis in terms of potential to improve cultivated chickpea (Cicer arietinum L.). Genetic Resources and Crop Evolution. DOI: 10.1007/s10722-017-0587-0.

Toker C, Erler F, Canci H, Ceylan FO (2010) Severity of leaf miner (Liriomyza cicerina Rond.) damage in relation to leaf type in chickpea. Turkish Journal of Entomology 34: 211-226.

Toker C, Canci H, Inci NE, Ceylan FO, Uzun B, Sonmez S, Citak S, Ikten C (2012) Pyramiding of the resistance to Fe-deficiency chlorosis and leaf miner (Liriomyza cicerina Rond.) in chickpea (Cicer arietinum L.) by mutation breeding. Turkish Journal of Field Crops 17: 41-45.

Toker C, Berger J, Abdullah K, Abdulkadir A, Canan C, Bekir B, Penmetsa RV, von Wettberg EJ, Cook DR (2014) Cicer reticulatum Ladizinsky, progenitor of the cultivated chickpea (C. arietinum L.). Legume Perspective 5: 26-27.

TUIK (2017) Türkiye İstatistik Kurumu. http://www.tuik.gov.tr/. Erişim Ağustos 2017.

Weigand S (1990) Insect pests of chickpea in the Mediterranean Area and possibilities for resistance. In: Saxena MC, Cubero JI, Wery J, (Eds), Present Status and Future Prospects of Chickpea Crop Production and Improvement in the Mediterranean Countries. Options Méditerranéennes-Série-Séminaries-no 9-CIHEAM, Paris, France, pp. 73-76. 